\title{
Fibre Lasers: The New Wave in Material Processing
}

\author{
David Parker ${ }^{1}$, David N Payne ${ }^{2}$ \\ ${ }^{1}$ SPI, 3 Wellington Park, Hedge End, Southampton SO30 2QU, United Kingdom \\ ${ }^{2}$ The Optoelectronic Research Centre, University of Southampton, Southampton
}

\begin{abstract}
In the last few years, fibre lasers have established themselves as the preferred laser source in many applications. The combination of small size, maintenance-free operation, thermal and electrical efficiency combined with outstanding (diffraction- limited) beam quality have made the fibre laser an attractive alternative to more established technologies. In fact, in some processes the fiber laser is the enabling technology.

Unique among high power lasers, the fiber laser is monolithic, the light being entirely confined to the fiber core. This gives immunity to thermal distortion of the beam, almost instant startup, very high stability and protection from the environment. Maintenance is minimal, since no realignment or cleaning of components is necessary.
\end{abstract}

In this review paper, we will:

- Give a brief historical perspective of the invention and development of the fibre laser from its inception in the early 1960's, through the first end-pumped single-mode demonstration in the mid1980's [1], to full commercial deployment [2].

- Describe a number of "state of the art" research results that not only demonstrate that the fibre laser can be scaled in power $[3,4]$, but is also capable of operating in a number of advanced modes, such as single-frequency, pulsed or tunable, and at a variety of wavelengths.

- Give a view of the near-term commercial exploitation of these results, and finally

- Propose some future steps for both the technology and application of this unique technology platform.

One of the key attributes of fiber lasers is their very high gain $(30 \mathrm{~dB})$ which results from their extended length. This allows the use of amplifiers as the preferred configuration, rather than oscillators, as used in most conventional lasers, giving far greater design freedom. As an indication of the extraordinary range of performance available from fiber lasers in c.w., pulse or single frequency regimes, the following results have been obtained recently in our laboratories:

\section{Oscillator Configuration}

- $1.4 \mathrm{~kW} 1070 \mathrm{~nm}$ ytterbium-doped fiber laser $\left(\mathrm{M}^{2}=1.4\right)$

- 600W polarized (PM) ytterbiumdoped fiber laser

- $120 \mathrm{~W}$ Q-switched ytterbium-doped fiber laser $(0.6 / 8.4 \mathrm{~mJ} /$ pulse $)$

- 200W $1550 \mathrm{~nm} \mathrm{Er/Yb} \mathrm{co-doped} \mathrm{fiber}$ laser

- $75 \mathrm{~W} \quad$ ytterbium-sensitized $2 \mu \mathrm{m}$ thulium-doped fiber laser 


\section{Master Oscillator/Power Amplifier Configuration (MOPA)}

- $633 \mathrm{~W}$ PM Yb fiber amplifier

- $511 \mathrm{~W}$ single-frequency $\mathrm{Yb}$ fiber amplifier

- $150 \mathrm{~W} \quad 1550 \mathrm{~nm}$ single-frequency $\mathrm{Er} / \mathrm{Yb}$ fiber amplifier

- $321 \mathrm{~W} 20 \mathrm{ps} 1 \mathrm{GHz} \mathrm{Er} / \mathrm{Yb}$ amplifier $(1550 \mathrm{~nm})$

- $25 \mathrm{~W} 100 \mathrm{fs} 5 \mathrm{MW}$ pk compressedpulse amplifier (1060nm)

While this selection of results serves to highlight the performance envelope, records are tumbling at every conference, leading to the question of what are the limits. Most noteworthy in the table above are the results for single frequency ( $20 \mathrm{kHz}$ linewidth), polarized laser output in a master oscillator/power amplifier (MOPA) configuration. Multiple amplifiers fed from a single seed source can be coherently beam combined provided they are polarized and narrow-linewidth. This provides a means of scaling fiber lasers from the current diffraction-limited record of $2.5 \mathrm{~kW}$ reported by IPG[5] to perhaps beyond $100 \mathrm{~kW}$ by stacking $\mathrm{kW}$ fiber lasers in beam-combined arrays with near-perfect beam quality. Moreover, the beam can be steered over a wide arc by phase controlling the outputs from each laser through, for example, fiber stretchers.

The MOPA configuration offers further advantages for pulsed lasers, as required in many processing applications. Under the operator's control and using a low-power diode laser seed, the output pulse from a multi-stage pulsed MOPA laser can be carefully shaped to optimize peak power and processing parameters. In fact, there is little need to use the traditional and often fragile Qswitching or mode-locking techniques, when better control can be obtained through amplification to the $\mathrm{kW}$ regime. This revolutionary concept has led, for example to a recent report of a $321 \mathrm{~W}$ Er:Yb MOPA operating at $1550 \mathrm{~nm}$ and giving $20 \mathrm{ps}$ pulses at $1 \mathrm{GHz}[6]$. At a commercial level, lasers giving $\sim 1 \mathrm{~mJ}, 100 \mathrm{~ns}$ pulse width at $10 \mathrm{kHz}$ prf are available.

Despite these impressive results, fibre laser development is still in its infancy. We can expect perhaps $10 \mathrm{~kW}$ output from a single diffraction-limited fibre, with several combining options for power-scaling to 100 's of $\mathrm{kW}$. Numerous pulse schemes are also available, giving pulses from 10 's of fs to 20 's of ns. Pulse energies up to $100 \mathrm{~mJ}$ can be obtained from large core designs. In pulse mode as well, scaling by beam combination should give at least a tenfold increase in energy/pulse and peak power.

Finally, wavelengths from $800 \mathrm{~nm}$ to $2.1 \mu$ and beyond are seamlessly available through appropriate choice of rare-earth dopant or through Raman shifting. This unique and powerful laser technology will increasingly be visible in the marketplace in coming years.

\section{References}

[1] RJ Mears, L Reekie, SB Poole and DN Payne, "Neodymium-doped silica singlemode fibre lasers," Electron. Lett,21, 738 (1985).

[2] See www.spioptics.com and www.ipgphotonics.com

[3] Y. Jeong, J. K. Sahu, D. N. Payne, and J. Nilsson, "Ytterbium-doped large-core fiber laser with $1 \mathrm{~kW}$ of continuous-wave output power," Electron. Lett., vol. 40, no. 8, pp. 470-472, 2004 
[4] D. N. Payne, Y. Jeong, J. Nilsson, J. K.

Sahu, D. B. S. Soh, C. Alegria, P. Dupriez, C.

A. Codemard, V. N. Philippov, V.

Hernandez, R. Horley, L. M. B. Hickey, L.

Wanzcyk, C. E. Chryssou, J. A. Alvarez-

Chavez, and P. W. Turner, "Kilowatt-class

single-frequency fiber sources", in Fiber

lasers II: technology, systems, and

applications, L. N. Durvasula, A. J. W.

Brown, and J. Nilsson, Eds., Proc. SPIE vol.

5709, pp. 133 - 141 (2005)

[5] V.P. Gapontsev, "High power, kilo-Watt class fiber lasers are winning and securing new opportunities in automotive and heavy industry", in Technical Summary Digest, Photonics West, San Jose, USA, 24-29 January 2004, LASE 2004, 5335-32, Session 6

[6] P.Dupriez, A.Piper, A.Malinowski, J.K.Sahu, M.Ibsen, Y.Jeong, L.M.B.Hickey, M.N.Zervas, J.Nilsson, D.J.Richardson, "321 W average power, $1 \mathrm{GHz} 20$ ps $1060 \mathrm{~nm}$ pulsed fiber MOPA source," OFC 2005 Anaheim 6-11 Mar 2005 (Postdeadline) 